ARTIGO TEMÁTICO: PÓS-GRADUAÇÃO E SERVIÇO SOCIAL

\title{
Pesquisa em Serviço Social: para onde caminhamos?
}

\author{
Emanuel Jones Xavier Freitas \\ Universidade Santo Amaro (UNISA)
}

\author{
Mayara Alves Reis \\ Universidade Santo Amaro (UNISA)
}

\section{Pesquisa em Serviço Social: para onde caminhamos?}

Resumo: A pesquisa em Serviço Social evidencia aspectos da realidade concreta no sentido de subsidiar uma adequada intervenção profissional no contexto social contemporâneo? Por meio do presente trabalho, busca-se elucidar a partir de levantamento bibliométrico, aspectos que permitam uma reflexão sobre as principais características das publicações científicas da Revista Serviço Social \& Sociedade no período de 2010 a 2016. Observou-se que as produções em Serviço Social ainda aludem a uma elevada contemplação teórica com ênfase na produção de revisões narrativas, sem fundar-se em aspectos concretos da vida social para desenvolver suas análises.

Palavras-chave: Serviço Social. Pesquisa social. Produção do conhecimento. Assistente social.

\section{Research on Social Work: where are we heading to?}

Abstract: Does research in Social Work highlight aspects of concrete reality in order to offer an appropriate professional intervention in the contemporary social context? Through the present work, based on bibliometric research, we seek to elucidate aspects that allow a debate about the main characteristics of scientific publications of the journal Serviço Social \& Sociedade in the period from 2010 to 2016. It was found that scientific productions in Social Work still allude to great theoretical contemplation with emphasis on the production of narrative reviews, without relying on specific aspects of social life to develop their analysis.

Keywords: Social Work. Social research. Production of knowledge. Social worker. 


\section{Introdução}

O compromisso histórico com a pesquisa social constitui-se como uma característica marcante do Serviço Social brasileiro. Desde seus primórdios, mesmo que sob uma orientação paradigmática já não mais privilegiada no cerne da profissão, o Serviço Social utiliza-se da pesquisa como importante ferramenta de trabalho para desvelar o aparente e apreender elementos que conduzam o assistente social à uma compreensão mais profunda sobre determinada situação. Qualificando a pesquisa social como um dos mais relevantes elementos constituintes do processo de trabalho profissional do assistente social, o presente artigo buscará evidenciar e refletir acerca das principais características contemporâneas impressas nas pesquisas realizadas no bojo do Serviço Social brasileiro e publicadas na Revista Serviço Social \& Sociedade, objetivando contribuir significativamente para o delineamento do estado da arte deste processo para a literatura nesta área do conhecimento.

O presente artigo justifica-se no sentido de colocar em pauta no contexto da profissão, uma reflexão sobre as peculiaridades da pesquisa social no cenário atual, de forma a conduzir-nos à leitura dos encaminhamentos dados a este importante elemento da formação e do exercício profissional no cenário presente, bem como, suas interlocuções para o enfrentamento de um importante desafio, sempre latente ao assistente social: o combate à dicotomia entre teoria e prática.

Para a consecução do presente trabalho, realizou-se uma pesquisa do tipo bibliométrico (PRITCHARD, 1969; FORESTI, 1989; PAO, 1989), de natureza qualitativa (GODOY, 1995) - portanto, não probabilística - e de nível descritivo (GIL, 2011) com a finalidade de evidenciar na literatura especializada em Serviço Social as principais características da pesquisa no contexto atual da profissão.

Inicia-se a discussão desenhando o contexto histórico da pesquisa no Serviço Social brasileiro, seguindo para uma análise de suas particularidades do cenário da profissão na contemporaneidade. Por conseguinte, apresenta-se os resultados da pesquisa, finalizando-se a discussão com as considerações dos autores sobre o processo de elaboração da pesquisa e dos resultados construídos. Entende-se, para a redação deste artigo, que o trabalho do assistente social se compõe por uma práxis social, construída na realidade concreta e alicerçada por um complexo de conhecimentos amparados no conjunto das ciências humanas e sociais: "Analisar a atuação profissional como práxis social requer um entendimento do trabalho em seu sentido concreto e abstrato a partir dos processos históricos, enfocando as alterações na produção e reprodução das relações capitalistas que determinam mudanças nas condições e relações de trabalho" (COSTA; MADEIRA, 2013, p. 102). Sob este ponto de vista, portanto, a pesquisa encontra assento especial e colocação da maior importância, uma vez que ao conceber a pesquisa como ferramenta, o assistente social terá a capacidade de explicitar elementos que o conduzam à compreensão mais aprofundada, permitindo-lhe o acesso à rudimentos mais adensados que o regerão ao efetivo exercício de uma leitura dialética ${ }^{1}$ da realidade concreta.

Diferente das abordagens clássicas sobre o papel da pesquisa nos processos de trabalho do assistente social, cujas tendem a um enfoque um tanto quanto contemplativo da realidade, na particularidade do presente trabalho, no entanto, persegue-se por objetivo desvelar os caminhos da pesquisa social nos últimos seis anos, a partir de um meticuloso processo de levantamento de informações. Entende-se, assim, que tanto quanto considerar a pesquisa social elemento fundamental à práxis, deve-se no contexto desta profissão, preocupar-se com a natureza das pesquisas em desenvolvimento no cerne da categoria profissional, bem como, com a forma como o exercício da pesquisa social tem contribuído com o desenvolvimento da profissão e, de especial forma, com as transformações no contexto da sociedade com fins a construção de uma nova ordem societária.

\section{Breve resgate da pesquisa no contexto do Serviço Social brasileiro}

A produção de conhecimento científico no Serviço Social brasileiro configura-se como um traço relativamente novo da profissão, datado de meados dos anos de 1970, quando do início do processo de reconceituação profissional (SETUBAL, 2005), que naquele momento, se caracterizava pela busca de uma relativa cientificidade que contribuísse para a legitimação do trabalho profissional no conjunto das diferentes instituições em que se inseria e demandava o trabalho do assistente social. Neste período, ainda, surgiram os primeiros cursos de pósgraduação no Brasil em ciências sociais, e especialmente, em Serviço Social, que potencializou, à luz do momento histórico já ilustrado, a elaboração de pesquisas no bojo desta profissão. No entanto, foi a partir da década de 1980 que efetivamente, considera-se que a pesquisa realizada nesta área tenha passado a oferecer pressupostos científicos para o exercício profissional, dando relativa sustentação para o trabalho no contexto contemporâneo. Para o exercício profissional, a produção do conhecimento científico possui relevante significância pois, busca viabilizar ao assistente social o conhecimento apurado da realidade concreta em que intervirá, de modo a reconhecer suas características, delineamentos, limites e possibilidades para então, desenvolver um 
processo de intervenção com vias à busca da efetiva transformação de uma determinada singularidade, com impactos à uma particularidade social:

O Serviço Social contemporâneo responde por uma significativa produção de conhecimentos nas mais diversas áreas e subáreas das ciências sociais. A partir dos anos de 1980, com maior evidência, a profissão se inseriu como interlocutora das demais áreas do conhecimento e começou a responder pela sua própria produção teórica, permitindo maior destaque à pesquisa acadêmica. A pesquisa que, necessariamente, gera a produção do conhecimento tornou-se pré-requisito ao assistente social, sendo que por meio da investigação científica, que na verdade é a sistematização de uma determinada realidade social, o profissional consegue apreender as intrincadas conexões do real e, assim, construir um caminho mais seguro para aproximarse de respostas concretas tão almejadas nas suas intervenções (LARA, 2007, p. 74).

Justifica-se, portanto, a relevância da pesquisa para o assistente social, posto que por sua natureza interventiva, há intrínseca à sua existência, a necessidade da execução de estratégias em pesquisa que permitam a construção do conhecimento para viabilizar novos caminhos, novas alternativas de enfrentamento às expressões da questão social, cotidianamente agudizadas pelas famélicas amarras do capitalismo contemporâneo, agravado pela crescente crise humanitária que a cada dia mais fortalece e fomenta o individualismo e o hedonismo como valores centrais da vida social. Para Iamamoto (2007, p. 239), o Serviço Social:

não se institucionaliza como uma ciência especial no quadro da divisão do trabalho. Essa especialização do trabalho não surge com a função precípua de produzir conhecimentos que articulem um campo 'peculiar do saber' [...] ainda que se inscreva oficialmente no campo das 'ciências sociais aplicadas'. O fato de o Serviço Social constituir-se uma profissão traz inerente uma exigência de ação na sociedade, o que não exclui a possibilidade e a necessidade de dedicar-se a investigações e pesquisas no amplo campo das ciências sociais e da teoria social.

Este cenário, tem demandado aos assistentes sociais, em seus diferentes campos sócio-ocupacionais, respostas profissionais qualificadas e institucionalizadas (GUERRA, 2000) com a finalidade de promover mudanças significativas ao contexto de vida da população usuária de seus serviços sociais, sendo a pesquisa, uma importante ferramenta para alcance deste objetivo. No entanto, para que a pesquisa social não seja reduzida ao status de simples instrumento de trabalho, mas considerada, especialmente, uma propulsora de reflexão para o crescimento da profissão e de seu papel na sociedade, faz-se necessária a construção de investigações que viabilizem a compreensão da conjuntura social, localizando e situando o papel do assistente social neste cenário. A este respeito, indicou Sposati (2007, p. 16) acerca dos desafios da pesquisa social ao Serviço Social:

esse desafio coloca a pesquisa como objeto do debate deslocando-a, portanto, da condição de meio, método, ferramenta fazendo-a alcançar um locus central para estudo. A concepção da pesquisa como mediação constitutiva da identidade e exercício profissional embora correta, tem levado profissionais do Serviço Social a algumas situações-armadilha, das quais destaco:

- a preponderância do debate sobre o método da pesquisa atribuindo caráter secundário ao objeto e aos resultados e à direção social do conhecimento;

- a banalização dos atributos necessários para o desempenho qualitativo na pesquisa, pelo pesquisador, o que termina por construir a falsa relação mecânica entre trabalho do profissional assistente social com a função de pesquisador.

Para que se supere este desafio, suplantar a concepção burguesa de pesquisa faz-se ressaltante. Compreende-se por concepção burguesa de pesquisa, aquela que reduz a produção do conhecimento à resolução de situações imediatas, não viabilizando o processo reflexivo de abstração teórica para alcance de novos conhecimentos, característica marcante da Era Moderna. Tal superação significa um salto qualitativo necessário para uma real transformação no modus operandi profissional, sem o qual passa-se a utilizar a pesquisa como um fim nela mesma, reduzindo a produção do conhecimento científico à resolução de problemas emergentes no exercício profissional cotidiano. Segundo Lara (2007, p. 75):

O conhecimento está fragmentado pelas condições de existência das instituições de pesquisa, com destaque à Universidade, que é responsável, dentro da divisão social do trabalho, pela sistematização do saber. O conhecimento moderno, fragmentado, resume-se numa dimensão de amparo às justificativas ideológicas conservadoras. Isso é explicado pelo crescimento das ciências naturais que, necessariamente, são voltadas 
para interesses práticos, ou seja, suas pesquisas potencializam o desenvolvimento industrial, tecnológico e as ramificações do desenvolvimento do capital e, por conseguinte, negam radicalmente a condição do trabalho em favor da lógica do capital. Nesse processo, as ciências sociais têm dificuldades de objetivar pragmaticamente os seus estudos e são deixadas em segundo plano no âmbito científico.

Ao compor a área de Ciências Sociais Aplicadas, o Serviço Social acaba por reproduzir tais características no desenvolvimento de suas pesquisas, especialmente aquelas voltadas para o exercício profissional. Nesta questão, observa-se na área, uma divisão perigosa entre: pesquisas desenvolvidas para subsídio ao exercício profissional e pesquisas desenvolvidas no interior das instituições educacionais, as quais muito pouco ou quase nunca estabelecem interlocução entre si.

\section{Considerações sobre produção do conhecimento no Serviço Social brasileiro contemporâneo}

Seria adequado afirmar que, seja direcionada para o exercício profissional, seja direcionada para a produção do conhecimento, a pesquisa consolida-se como ferramenta basilar para o avanço do Serviço Social como profissão, muito embora ainda sejam grandes os desafios a serem superados, especialmente no enfrentamento à dicotomia teoria/prática: “muitos caminhos ainda estão para ser percorridos até que aconteça o total desvencilhamento do Serviço Social com o ideário positivista que divide o agir do homem em campos automáticos e independentes, que estabelece uma dicotomização entre teoria e prática, até mesmo nas experiências em pesquisa" (SETUBAL, 2005, p. 167).

No entanto, mais importante do que elaborar e desenvolver determinado processo de pesquisa, faz-se relevante e notadamente necessária a publicização dos dados de pesquisa, não apenas como contrapartida à sociedade por ter figurado como sujeito, mas pela finalidade de capilarizar o aprendizado, reproduzindo o conhecimento e contribuindo para o avanço técnico-científico desta área profissional. Com efeito, embora não seja possível confirmar a priori tal informação, sugere-se, a partir da observação das práticas cotidianas, no caso do Serviço Social, uma determinada tendência à centralidade da publicação de pesquisas sociais oriundas de trabalhos demandados por disciplinas cursadas por assistentes sociais em pós-graduações do tipo Stricto Sensu, não apenas para o cumprimento de exigências programáticas destes cursos, mas pela viabilidade do encaminhamento de publicações, dadas as requisições institucionais pelo "produtivismo acadêmico" ' (CHAUÍ, 2003; SGUISSARDI, 2010). Este apontamento não é realizado, no entanto, de forma a exprobar aqueles que se utilizam da oportunidade de publicar em razão de uma necessidade objetiva de fazê-lo, mas como observação de um processo que dificilmente sur-

mais importante do que elaborar e desenvolver determinado processo de pesquisa, faz-se relevante e notadamente necessária a publicização dos dados de pesquisa, não apenas como contrapartida à sociedade por ter figurado como sujeito, mas pela finalidade de capilarizar o aprendizado ... ge do ímpeto de produzir conhecimento a partir da práxis nela mesma, ou seja, do desejo e/ou necessidade de se refletir o exercício profissional e dele, produzir conhecimento. Segundo Setubal (2005, p. 34):

Não é raro encontrar pesquisas, sobretudo no meio acadêmico, que tratam de problemas remotos e são destituídas de interpretação mais ampla e acurada. Muitas são as que se voltam para a elaboração do conhecimento apenas como conhecimento, isto é, um conhecimento que vagueia pela realidade sem contudo dar conta dela no concretismo da sua história. Admitimos que todas essas questões se relacionam aos significados e significantes da pesquisa e por isso estão imbricadas nas suas finalidades sociais.

Para efeito ilustrativo, apresenta-se a seguir o cenário da busca pela formação como pesquisador, perseguida como objetivo dos programas de pós-graduação Stricto Sensu. Realizou-se levantamento junto ao Sistema de Informações Georreferenciadas da Coordenação de Aperfeiçoamento de Pessoal de Nível Superior (GEOCAPES), tendo como referência os anos de 2013 e 2015, a fim de construirmos uma base objetiva à discussão em curso. 
Para a finalidade deste levantamento, considerou-se a formação de mestres em Serviço Social, cuja legislação determina duração mínima de 18 meses (ingresso em 2013 e encerramento em 2015), esperando-se que o aluno o conclua em 24 meses, a fim de atender aos requisitos de qualidade estabelecidos pelos diferentes programas de pós-graduação distribuídos em todos o Brasil. A respeito do levantamento realizado, obteve-se o seguinte resultado:

Tabela 1 - Distribuição de alunos em Stricto Sensu (mestrado) em diferentes áreas do conhecimento

\begin{tabular}{|c|c|c|c|}
\hline \multicolumn{2}{|c|}{ Mestrado Acadêmico (2013-2015) } \\
\hline$\#$ & Área do Conhecimento & Entrada (2013) & Saída (2015) \\
\hline 1 & Educação & 6.586 & 2.975 \\
2 & Ciências Agrárias I & 5.906 & 2.608 \\
3 & Interdisciplinar & 5.791 & 2.523 \\
4 & Letras / Linguística & 5.826 & 2.328 \\
5 & Direito & 5.084 & 2.119 \\
6 & Engenharias III & 4.234 & 1.609 \\
7 & Administração, Ciências Contábeis e Turismo & 3.117 & 1.496 \\
8 & Biodiversidade & 3.350 & 1.486 \\
9 & Psicologia & 2.963 & 1.300 \\
10 & Engenharias I & 3.430 & 1.264 \\
\hline
\end{tabular}

Fonte: Elaborado pelos autores.

O Serviço Social como área do conhecimento, figura como $40^{\mathrm{a}}$ área em quantidade de alunos nos programas de mestrado no cenário nacional, em programas de pós-graduação recomendados pela Fundação Coordenação de Aperfeiçoamento de Pessoal de Nível Superior (CAPES), sendo que dos ingressantes, ao que indicam os números, apenas $29 \%$ concluem o curso nos 24 meses previstos em legislação.

Ampliando a ilustração anteriormente proposta, para avaliação dos cursos de doutoramento, tem-se o seguinte resultado:

Tabela 2 - Distribuição de alunos em Stricto Sensu (doutorado) em diferentes áreas do conhecimento

\begin{tabular}{|c|c|c|c|}
\hline \multicolumn{2}{|c|}{ Doutorado (2013-2015) } \\
\hline$\#$ & Área do Conhecimento & Entrada (2013) & Saída (2015) \\
\hline 1 & Ciências Agrárias I & 5.077 & 1.301 \\
2 & Educação & 4.490 & 1.111 \\
3 & Letras / Linguística & 4.075 & 989 \\
4 & Medicina I & 2.758 & 683 \\
5 & Medicina II & 2.488 & 636 \\
6 & Biodiversidade & 2.538 & 608 \\
7 & Química & 2.866 & 584 \\
8 & Ciências Biológicas II & 2.509 & 578 \\
\hline 9 & Odontologia & 1.838 & 571 \\
46 & Engenharias II & 2.762 & 548 \\
\hline
\end{tabular}

Fonte: Elaborado pelos autores. 
Sob a perspectiva de análise dos concluintes em doutorado, com duração média de 48 meses, a partir dos dados extraídos da mesma base de dados, observa-se que o Serviço Social como área do conhecimento, se coloca na $46^{\mathrm{a}}$ posição, quando comparado às demais áreas, alcançando $16 \%$ de efetividade na formação de novos doutores no cenário nacional, quando a média nas 10 áreas que mais formam pesquisadores é de 19,6\%. Comparados, entre alunos de mestrado e doutorado de todas as áreas do conhecimento, o Serviço Social coloca-se no $45^{\circ}$ lugar.

Acerca do quantitativo de assistentes sociais em pós-graduações Stricto Sensu em comparação a outras áreas melhor colocadas nos indicadores apresentados (GEOCAPES), a exemplo da odontologia $\left(9^{\circ}\right)$ a eventual retórica da quantidade de profissionais existentes parece não ser verdadeira. Segundo estimativas dos conselhos de classe, atualmente no Brasil existem em média 135 mil assistentes sociais, em detrimento de 219 mil dentistas. Cenário em que no período de 2012 a 2015, formaram-se proporcionalmente $0,38 \%$ assistentes sociais pesquisadores e 1,26\% de odontólogos pesquisadores, isto é, mais que o triplo.

Distante de uma simples tentativa de ranqueamento das diferentes áreas do conhecimento em relação à formação de pesquisadores, pretendeu-se por meio do levantamento anterior apresentar o grave cenário em que figura o Serviço Social na produção do conhecimento científico brasileiro, especialmente num panorama em que se destaca a produção científica no cerne da instituição universitária. Em contrapartida aos dados quantitativos absolutos, merece destaque o processo de qualificação das pesquisas em desenvolvimento no bojo do Serviço Social nos últimos anos, dado que sob o ponto de vista da internacionalização, por exemplo: "o Serviço Social tem reforçado sua interlocução com Programas localizados particularmente na Europa, e tem participado ativamente do processo de criação e consolidação da pós-graduação na América Latina” (CAPES, 2013, p. 36).

\section{O modus operandi da pesquisa em Serviço Social no Brasil: de 2010 a 2016}

Na direção de contribuir para a reflexão sobre os direcionamentos que na atualidade nos apontam a pesquisa em Serviço Social, desenvolveu-se um levantamento bibliométrico com a finalidade de delinear a condição das publicações em Serviço Social, a partir de um recorte da literatura periódica nacional. Por levantamento bibliométrico, compreende-se a tentativa de quantificar os processos de comunicação escrita (PRITCHARD, 1969; FORESTI, 1989; PAO, 1989), a partir de parâmetros claros e bem definidos. Para tanto, definiu-se como base de dados para pesquisa a Revista Serviço Social \& Sociedade, considerando um dos periódicos científicos mais significativos da área de Serviço Social no cenário brasileiro e internacional, avaliado como publicação do tipo Qualis A1.

A classificação Qualis é um parâmetro utilizado para qualificar as publicações realizadas por determinadas revistas científicas, em dadas áreas do conhecimento. As publicações são enquadradas em estratos indicativos de qualidade, sendo A1 o mais elevado, seguido de A2, B1, B2, B3, B4, B5 e C.

A classificação é realizada pelos comitês de consultores de cada área de avaliação seguindo critérios previamente definidos pela área e aprovados pelo CTC-ES, que procuram refletir a importância relativa dos diferentes periódicos para uma determinada área. Os critérios gerais e os específicos utilizados em cada área de avaliação da CAPES estão disponibilizados nos respectivos Documentos de Área (CAPES, 2016).

Delimitado o estrato do periódico científico, definiu-se como parâmetros para análise das publicações a) o período em indexação entre 2010 e 2016, b) a natureza das pesquisas publicadas no periódico em questão, c) os tipos de pesquisa realizadas e publicadas no periódico e ainda, d) os níveis de pesquisa alcançados pelas publicações em questão.

Os dados foram pré-categorizados da seguinte forma: 


\section{Tabela 3 - Definição teórica das categorias definidas a priori}

\begin{tabular}{|c|c|}
\hline Categorias a priori & Definição teórica das categorias definidas a priori \\
\hline $\begin{array}{l}\text { a) o período em indexação entre } 2010 \text { e } \\
2016\end{array}$ & Total de 157 artigos analisados, publicados entre janeiro de 2010 e agosto de 2016. \\
\hline b) a natureza das pesquisas publicadas & $\begin{array}{l}\text { Por natureza da pesquisa, compreende-se o resultado da fonte dos dados. Questão a } \\
\text { qual possibilita dividi-las em dois grupos, sendo elas pesquisas puras e pesquisas } \\
\text { aplicadas. Pesquisas puras são aquelas que buscam conhecer ou aprofundar discus- } \\
\text { sões baseando-se especialmente em abstrações conceituais (BARROS; LEHFELD, } \\
\text { 2000). Busca, em geral, discorrer sobre uma questão intrigante acerca da realidade } \\
\text { numa abordagem teórico-conceitual (TACHIZAWA; MENDES, 2006). Em relação à } \\
\text { pesquisa aplicada, de acordo com Barros e Lehfeld (2000, p. 78), a pesquisa aplicada } \\
\text { possui por objetivo a necessidade de gerar conhecimento para aplicação concreta de } \\
\text { seus resultados, tendo como função "contribuir para fins práticos, visando à solução } \\
\text { mais ou menos imediata do problema encontrado na realidade". }\end{array}$ \\
\hline $\begin{array}{l}\text { c) os tipos de pesquisas realizadas e } \\
\text { publicadas }\end{array}$ & $\begin{array}{l}\text { Dividem-se entre qualitativa e quantitativas. Pesquisas qualitativas estão preocupa- } \\
\text { das "com o processo e não simplesmente com o resultado ou produto" (GODOY, } \\
\text { 1995, p. 63). Neste tipo de pesquisa, o interesse do investigador está voltado à } \\
\text { observação e elucubração acerca dos fenômenos que se manifestam por meio de } \\
\text { atividades, procedimentos e diferentes tipos de interação. Ao contrário, na pesquisa } \\
\text { quantitativa "o pesquisador conduz seu trabalho a partir de um plano estabelecido a } \\
\text { priori, com hipóteses claramente especificadas e variáveis operacionalmente defini- } \\
\text { das", preocupando-se estritamente "com a medição objetiva e a quantificação dos } \\
\text { resultados" (GODOY, 1995, p. 58). }\end{array}$ \\
\hline $\begin{array}{l}\text { d) os níveis de pesquisa alcançados pe- } \\
\text { las publicações }\end{array}$ & $\begin{array}{l}\text { Segundo Gil (2011), cada pesquisa social possui um objetivo em especial, o que } \\
\text { viabiliza-nos agrupá-las, a critério de ordenamento, em um dado número de } \\
\text { grupamentos amplos. Selltiz et al. (1962 apud. GIL, 2011, p. 27) classificam as } \\
\text { pesquisas em três grupos, sendo eles 1) estudos exploratórios, 2) estudos descritivos } \\
\text { e 3) estudos explicativos. }\end{array}$ \\
\hline
\end{tabular}

Fonte: Elaborado pelos autores.

A partir do estabelecimento dos procedimentos metodológicos de pesquisa já apresentados, passou-se a analisar a literatura, com a finalidade de extrair dela, significado para as reflexões que seguem.

Sob o ponto de vista da natureza das pesquisas publicadas na Revista Serviço Social \& Sociedade no período em questão (de 2010 a 2016), observa-se uma acentuada predominância de pesquisas puras (93\%) em relação às pesquisas aplicadas (7\%). Isto é, o periódico caracteriza-se por ser uma publicação de cunho genuinamente teórico, caracterizadas por elevados níveis de abstração, não demandando dados da realidade para definição das conclusões apresentadas. Nestes casos, trata-se majoritariamente de pesquisas desenvolvidas a partir de dados secundários, constituídos pelo conteúdo existente em livros ou artigos científicos. Embora em muitas áreas do conhecimento estas pesquisas se utilizem de dados secundários da realidade para desenvolvimento de suas elucubrações, no caso das publicações produzidas no bojo do Serviço Social e expecificamente no periódico em questão, observou-se que as revisões de literatura realizadas preocupam-se com discussões teórico-conceituais pautadas em aspectos alheios ao cotidiano, isto é, não relativos direta e objetivamente aos aspectos da vida concreta cotidiana:

A formação de pesquisadores no Serviço Social tem se deparado com muitas dificuldades. Essas, na sua abrangência, tanto dizem respeito às questões extrapolentes à prática profissional como às que lhe são inerentes, como, por exemplo, a indefinição de prioridades temáticas e objetivos. Porém, o que nos parece mais preocupante é a complexidade e amplitude com que o Serviço Social tem tratado os seus objetos de investigação. Esses, em muitos casos, são transformados em problemáticas inconsistentes que, ao procurar abarcar uma pluralidade de temas, diluem as suas preocupações teóricas; esquece-se, muitas vezes, de colocar, no centro das suas reflexões, o próprio Serviço Social como prática concreta (SETUBAL, 2005, p. 111). 
No que diz respeito à natureza das pesquisas realizadas na área do Serviço Social, observa-se preponderância de pesquisas de natureza qualitativa (86\%), estratégia de pesquisa característica das ciências sociais aplicadas, que no cenário contemporâneo se destacam por absorver

as temáticas do pós-modernismo para objetar a racionalidade tecnoinstrumental, que comanda a pesquisa convencional, a fim de revelar a originalidade criadora da investigação ou recorrem às sensibilidades, que o pós-modernismo invoca para analisar as possibilidades estéticas dos estilos discursivos ou textuais da pesquisa ou, enfim, recorrem ao pós-modernismo, como crítica política às relações de poder e dominação, que subjazem às relações de classe, neutralidade e apresentar os mútiplos focos de coerção e poder que uma investigação acurada descobre (CLOUGH, 1994; APPLE, 1996; BEHAR; GORDON, 1995; CARPECKEN, 1999; NICHOLSON; SIEDMAN, 1995). (CHIZZOTTI, 2014, p. 56).

A abordagem realizada pelos trabalhos, no entanto, não se configura a partir dos ditames da utilização de estratégias práticas de pesquisa - como viu-se no indicador anteriormente analisado -, mas de uma reflexão com centralidade bibliográfica, do estabelecimento do diálogo entre distintas abordagens paradigmáticas (comensuráveis ou incomensuráveis), sobre a qual a metodologia de pesquisa não se define por completo a partir dos modelos de pesquisa pré-existentes, mas sugerindo trabalhos caracterizados como "revisões narrativas":

Os artigos de revisão narrativa são publicações amplas, apropriadas para descrever a discutir o desenvolvimento ou o "estado da arte" de um determinado assunto, sob o ponto de vista teórico ou contextual. As revisões narrativas não informam as fontes de informação utilizadas, a metodologia para busca das referências, nem os critérios utilizados na avaliação e seleção dos trabalhos. Constituem, basicamente, de análise da literatura publicada em livros, artigos de revistas impressas e/ou eletrônicas na interpretação e análise crítica pessoal do autor (ROTHER, 2007, p. 1).

Sob o aspecto dos níveis de pesquisa (GIL, 2011) alcançados pelas pesquisas em Serviço Social, publicadas no peródico científico, observou-se a seguinte dispersão:

\section{Gráfico 1 - Distribuição da quantidade de pesquisas por níveis}

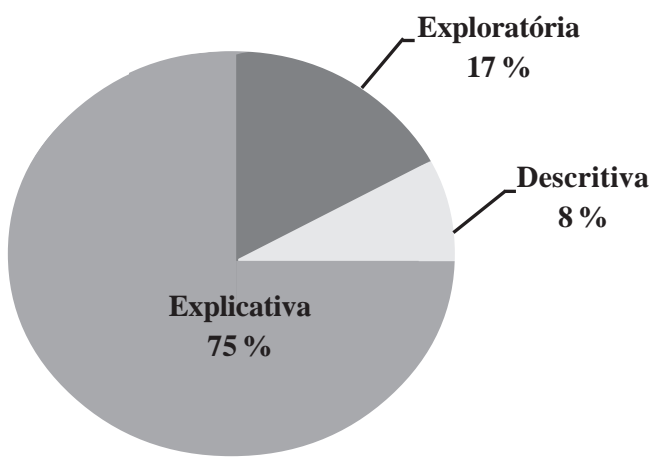

Fonte: Elaborado pelos autores.

Os níveis de pesquisa são as distinções necessariamente construídas em razão dos diferentes objetivos que se almeja alcançar em razão da pesquisa realizada. Os níveis de pesquisa estão intrinsecamente relacionados ao objeto e ao tema da pesquisa a ser realizada, pois contribui para a definição das estratégias metodológicas de pesquisa, especialmente no que diz respeito ao aspecto instrumental (exceto no caso de uma revisão narrativa, em que estes aspectos são desconsiderados). Em razão do levantamento realizado para o presente estudo, percebeuse na literatura analisada uma recorrência de $75 \%$ de pesquisas de nível explicativo. Pesquisas de nível explicativo apresentam finalidade central em "identificar os fatores que determinam ou que contribuem para a ocorrência dos fenômenos" (GIL, 2011, p. 28). É considerada o tipo de pesquisa mais profunda, pois envolve um nível maior de complexidade para apuração das informações, no caso do Serviço Social, de cunho teórico. 
Em contrapartida, $17 \%$ das pesquisas publicadas pelo periódico em análise referem-se àquelas de nível exploratória: "Pesquisas exploratórias são desenvolvidas com o objetivo de proporcionar visão geral, de tipo aproximativo, acerca de determinado feito. Este tipo de pesquisa é realizado especialmente quando o tema escolhido é pouco explorado e torna-se difícil sobre ele formular hipóteses precisas e operacionizáveis” (GIL, 2011, p. 27).

As pesquisas deste nível buscam viabilizar o desenvolvimento e o reconhecimento de novas ideias, visualizar novos conceitos e possibilidades, além da formulação de novos problemas para definição de hipóteses a serem pesquisadas e estudos posteriores com maior profundidade. Dos três níves de pesquisa consensuados a partir de uma abordagem teórica, sugere-se que pesquisas de nível exploratório são as que demandam menos rigor metodológico na abordagem do objeto de estudo, em razão do desconhecimento prévio acerca da situação em análise, no entanto, se constitituem por relevante importância e reconhecimento social, dadas as contribuições a partir de novas abordagens e alternativas que se constroem: "habitualmente envolvem levantamento bibliográfico e documental, entrevistas não padronizadas e estudos de caso. Procedimentos de amostragem e técnicas quantitativas de coleta de dados não são costumeiramente aplicados nesta pesquisa" (GIL, 2011, p. 27).

Figuram como pesquisas descritivas, $8 \%$ dos artigos publicados no periódico analisado. Pesquisas deste nível, são aquelas que buscam, a partir da eleição de um tema a ser pesquisado, definir critérios para a descrição do fenômeno ou sujeitos envolvidos, de forma a elucidar características que viabilizem a identificação de aspectos relacionados a opiniões, comportamentos, entre outras particularidades do objeto ou sujeito(s) em estudo.

\section{Considerações finais}

São diversas as reflexões que emergem no processo de análise dos dados em detrimento do estudo realizado, no entanto, cabe-nos a tarefa de elencá-las de forma objetiva para que não nos furtemos de pontuálas em sua totalidade:

1. O presente trabalho não se resume a um julgamento ao padrão das publicações científicas em Serviço Social, mas a uma reflexão a partir de dados concretos, acerca do caminho para o qual acenamos tendo por base as publicações de um dos mais importantes periódicos brasileiros, a Revista Serviço Social \& Sociedade, no período de 2010 a 2016.

2. O estudo ora realizado, resumiu-se à análise do periódico indicado, não compreendendo consulta ao conteúdo das teses, dissertações ${ }^{3}$ e artigos de outras revistas que podem contribuir tanto quanto para subsídio à ação profissional.

Nestes termos, observados os recortes do estudo, apresentam-se as considerações a serem pontuadas a partir da pesquisa realizada:

1. Analisando os resultados correspondentes à natureza das pesquisas publicadas no periódico, sugere-se que pela centralidade das publicações de natureza pura ou teórica, tais pesquisas estejam contribuindo menos que o cogente para subsidiar as ações profissionais dos assistentes sociais de base, ou seja, o periódico que teria por objetivo contemporaneizar as abordagens profissionais, acaba por diminuir sua efetividade ao não apresentar propostas de respostas às necessidades impressas e substancializadas no exercício profissional. Isso não significa a cega defesa por publicações vazias de uma abordagem teórica, no entanto, sugere-se que para efeito de uma publicação periódica, a abordagem sustentada pela revisão narrativa não deve ser considerada um fim nela mesma, especialmente pela pessoalidade arraigada, tão recorrente nas publicações analisadas.

2. Sob o ponto de vista do tipo de pesquisa dos artigos publicados, sugere-se que a proeminência de pesquisas qualitativas correspondam às expectativas desta àrea do conhecimento, quando mais importante que totalizar sob o ponto de vista matemático a realidade social - que é mutável, dinâmica e complexa -, faz-se mister para o assistente social a compreensão da realidade sob o ponto de vista seu significado, sentido e profundidade de acepção.

3. Quanto aos níveis de pesquisa alcançados pelas publicações, relacionando-os aos resultados referentes à natureza da pesquisa, sugere-se a existência de um cenário preocupante. A associação do saldo de pesquisas puras $(93 \%)$ ao de pesquisas de nível explicativo $(75 \%)$, indica que há uma centralidade no aprofundamento que questões genuinamente teóricas, agravada pela intensa recorrência de revisões narrativas. Tal situação agudiza a dicotimia teoria vs prática, ao não estabelecer uma relação direta com dados primários de pesquisa, e ainda, incorre num tal nível de 
contemplação que acaba por tornar inatingível o alcance de reflexividade, a depender do perfil do leitor que possivelmente, em alguns casos, poderá não enxergar sentido na reflexão ali apesentada, por mais significativa que esta seja para a ação profissional.

Diante dos apontamentos realizados, avalia-se necessário que docentes, discentes, pesquisadores e assistentes sociais em geral reavaliem sua postura em relação ao exercício da pesquisa no contexto da profissão, não apenas fomentando o exercício da pesquisa para além do cumprimento das demandas imediatas (sejam elas do exercício profissional ou acadêmico), mas para a promoção de novas reflexões e construção de novas possibilidades para o trabalho profissional que contribuam com o desenvolvimento da categoria dos assistentes sociais brasileiros, bem como, contribua substancialmente à construção cotidiana de uma nova ordem societária.

\section{Referências}

BARROS, A. J. S.; LEHFELD, N. A. S. Fundamentos de Metodologia: Um Guia para a Iniciação Científica. 2. ed. São Paulo: Makron Books, 2000.

BRASIL. Coordenação de Aperfeiçoamento de Pessoal de Nível Superior. Documento de Área 2013 - Área de Avaliação Serviço Social. Brasília, 2013.

. Coordenação de Aperfeiçoamento de Pessoal de Nível Superior. Classificação da produção intelectual. 2016. Disponível em: <http://www.capes.gov.br/avaliacao/instrumentos-de-apoio/classificacao-da-producao-intelectual>. Acesso em: 06 out. 2016.

CHAUÍ, M. A universidade pública sob nova perspectiva. Revista Brasileira de Educação, Rio de Janeiro, n. 24, p. 5-15, set./out./nov./ dez. 2003.

CHIZZOTTI, A. Pesquisa qualitativa em ciências humanas e sociais. 6. ed. Petrópolis, RJ: Vozes, 2014.

COSTA, R. G; MADEIRA, M. Z. A. Trabalho, práxis e Serviço Social. Revista Katálysis, Florianópolis, v. 16, n. 1, p. 101-110, 2013. FORESTI, N. A. B. Estudo da contribuição das revistas brasileiras de Biblioteconomia e Ciência da Informação enquanto fonte de referência para a pesquisa. 1989. 209 f.: il. Dissertação (Mestrado) - Departamento de Biblioteconomia, Faculdade de Estudos Sociais e Aplicados, Universidade de Brasília, Brasília, DF, 1989.

GIL, A. C. Métodos e Técnicas de Pesquisa Social. 6. ed. 4. reimpr. São Paulo: Atlas, 2011.

GODOY, A. S. Introdução à pesquisa qualitativa e suas possibilidades. Revista de Administração de Empresas, São Paulo, v. 35, n. 2, p. 57-63, mar./abr. 1995.

GONÇALVES, M. C. V.; ANDRADE, M. T. Produção de conhecimento: análise de dissertações. In: ENCONTRO NACIONAL DE PESQUISADORES EM SERVIÇO SOCIAL - ENPESS, 15., 2016, Ribeirão Preto. Anais... Ribeirão Preto: ABEPSS, 2016. 1 CDROM.

GUERRA, Y. Capacitação em Serviço Social e Política Social: o trabalho do assistente social e as políticas sociais. Módulo 4. Programa de capacitação continuada para assistentes sociais. Brasília: CEAD, 2000.

IAMAMOTO, M. V. Serviço Social em tempo de capital fetiche: capital financeiro, trabalho e questão social. São Paulo: Cortez, 2007. LARA, R. Pesquisa e Serviço Social: da concepção burguesa de ciências sociais à perspectiva ontológica. Revista Katálysis, Florianópolis, v. 10, n. esp., p. 73-82, 2007.

PAO, M. L. Concepts of information retrieval. Englewood, Colorado: Libraries Unlimited Inc., 1989.

PRITCHARD, A. Statistical bibliography or bibliometric? Journal of Documentation, [s. 1.], v. 25, n.4, p. 348-349, dez/1969.

ROTHER, E. T. Revisão sistemática x revisão narrativa. Acta Paulista de Enfermagem, São Paulo, v. 20, n. 2, p. 5-6, junho/2007.

SETUBAL, A. A. Pesquisa em serviço social: utopia e realidade. 3. ed. São Paulo: Cortez, 2005.

SGUISSARDI, V. Produtivismo acadêmico. In: OLIVEIRA, D. A.; DUARTE, A.; VIEIRA, L. (Orgs.). Dicionário de Trabalho, Profissão e Condição Docente. Belo Horizonte: Faculdade de Educação/UFMG, 2010.

SPOSATI, A. Pesquisa e produção de conhecimento no campo do Serviço Social. Revista Katálysis, Florianópolis, v. 10, n. esp., p. 1525, 2007.

TACHIZAWA, T.; MENDES, G. Como fazer monografia na prática. 12. ed. Rio de Janeiro: Editora FGV, 2006.

\section{Notas}

1 Dialética não compreendida apenas como uma abstração da realidade, mas numa perspectiva materialista de compreensão da realidade a partir de uma abordagem dialética, tal qual abordada por Engels e Marx.

2 Fenômeno desencadeado pelos processos desenvolvidos com a finalidade de avaliar o desempenho acadêmico das instituições de ensino públicas e privadas, a partir do intenso processo de produção acadêmico mediado por publicações em revistas e papers nacionais e internacionais, gerando-se uma centralidade no aspecto quantitativo da produção, em detrimento do aspecto qualitativo de produção do conhecimento científico. 
3 Sobre esta questão, faz-se relevante o estudo desenvolvido por Gonçalves e Andrade (2016, p. 10) a respeito da produção científica no Programa de Pós-Graduação em Serviço Social da Universidade Federal de Sergipe, o qual a pontua que "as dissertações, em sua maioria, fizeram uso da pesquisa documental e bibliográfica para produção de conhecimento".

\section{Emanuel Jones Xavier Freitas}

ejxfreitas@gmail.com

Mestre em Administração pela Universidade Presbiteriana Mackenzie (UPM)

Professor do curso de Serviço Social da Universidade Santo Amaro (UNISA)

\section{Mayara Alves Reis}

may.a.v@ hotmail.com

Graduanda do curso de Serviço Social da Universidade Santo Amaro (UNISA)

\section{UNISA}

Rua Isabel Schmidt, 349, Santo Amaro

São Paulo - São Paulo - Brasil

CEP: 04743-030 